\title{
Impact of Followup Visits on the Integrated Management of Childhood and Neonatal Illness Strategy Implementation in the Health Facilities of District Jamshoro
}

\author{
Mumtaz Mahesar, Salma Shaikh, Muhammad Nadeem Chohan, Muhammad Hanif, \\ Afshan Sultana Zia Mahesar
}

\begin{abstract}
OBJECTIVE: To compare the impact of monthly versus quarterly monitoring visits on the IMNCI case management skills of health workers in the health facilities of district Jamshoro.

METHODOLOGY: Comparative Cross-sectional study was conducted at 4 Health facilities of District Jamshoro, from January to December 2015. There were total four Integrated Management of Childhood and Neonatal IIIness (IMNCI) trained staff, one at each health facility. Health facilities having Integrated Management of Childhood and Neonatal IIIness (IMNCl) trained staff were included in this study; while Health facilitieshaving IMNCI untrained medical staff were excluded. Staff were trained by trainors during nine days IMNCI workshop. During training they were trained specifically about the detectoion of general danger signs, respiratory distress, dehydration, Throat / Ear infections, malaria and measles.

RESULTS: Monthly monitoring visits had better results than the quarterly monitoring visits; regarding the detectoion of general danger signs, respiratory distress, dehydration, Throat / Ear infections, malaria and measles. Out of 4 health facilities 2 health facilities were visited on monthly basis (Taluka head Quarters Kotri and Government Dispensary Lower Sindh Barrage) and other 2 on quarterly basis (Government Dispensary Petaro OPD and Government Dispensary Christian colony), competency of

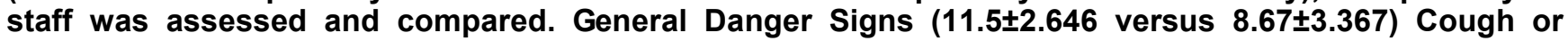
Difficult Breathing $(13 \pm 1.826$ versus $8.83 \pm 3.070)$, Diarrhea $(13 \pm 1.826$ versus $8.83 \pm 3.070)$, Sore Throat (11.5 \pm 2.646 versus 8.67 \pm 3.367$)$, Ear Problem (11.5 \pm 2.64 versus $8.67 \pm 3.367)$, malaria (12.25 \pm 3.096 versus $8.83 \pm 3.070)$ and measles $(11.75 \pm 2.630$ versus $8.75 \pm 3.223)$

CONCLUSIONS: We concluded that monthly follow-up visits had very good impact on the IMNCl strategy implementation in health facilities. Monitoring progress and evaluating results are key functions to improve the performance of those responsible for implementing health services.
\end{abstract}

KEY WORDS: Integrated Management of Childhood and Neonatal Illness, Health Facilitiess.

This article may be cited as: Mahesar M, Shaikh S, Chohan MN, Hanif M, Mahesar ASZ. Impact of Followup Visits on the Integrated Management of Childhood and Neonatal Illness Strategy Implementation in the Health Facilities of District Jamshoro. J Liaquat Uni Med Health Sci. 2020;19(02):87-92. doi: 10.22442/jlumhs.201920668

\section{INTRODUCTION}

Childhood mortality is about 10 million all over the world. It includes 4-million neonatal death each year ${ }^{1}$. Most of these childhood deaths can be prevented by the training of health workers especially in poor developing countries ${ }^{2}$. Pakistan is also a poor developing country, there are consistently poor neonatal and child health indicators, and it is ranked 43 among high childhood mortality rate countries ${ }^{3}$.

Infant mortality rate in Pakistan is 61.2-per 1000 live births. Pakistan is ranking third in Asian countries, having high $<5$ years old mortality. Under 5 years' mortality rate is 74.1-per 1000 live births. High childhood and neonatal mortality rates are major global health challenges ${ }^{4}$. The fourth Millennium Development Goal (MDG-4) commitment was to reduce mortality in children younger than 5 years by two-third between 1990 and $2015^{5}$, especially neonatal mortality (38\% of all deaths in children less than five) in high-mortality countries is needed ${ }^{6}$.

Although between 1960 to 2000 , there was reduction in child mortality (from 2 months to age 5 years); unfortunately, the neonatal mortality rate (NMR) could not be reduced desirably?

Individualized clinical care can reduce the mortality rate in $<5$ years' age children including neonates ${ }^{8}$.

For the provision of individualized care, $\mathrm{WHO}$ and UNICEF launched Integrated Management of Childhood Illness (IMCI) strategy during 1992 followed by Integrated Management of Childhood and Neonatal Illness (IMNCI) strategy to improve child and neonatal survival. Government of Pakistan adopted these IMNCI strategies in 1998 as National guidelines ${ }^{9}$.

Our hypothesis is that the health workers who were trained in $I \mathrm{MNCl}$ case management, loose the competency with the passage of time and the impact of training is diminished. This study is conducted to 
know the health care competence regarding the $I \mathrm{MNCl}$ case management after the frequent monitoring visits.

\section{METHODOLOGY}

This Comparative Cross sectional study was done at 4 dispenseries of district Jamshoro (having the IMNCI trained staff) by random sampling from January to December 2015. There were total four IMNCI trained staff, one at each health facility. There were total 22 health care facilities in district Jamshoro among them 6 have trained health personals. Four Health facilities having trained IMNCl staff were included in this study while, two health facility having trained (trained staff were unavailable during study period because of leave for higher studies) and 16 having untrained $\mathrm{IMNCl}$ medical staff were excluded from the study. Interview was taken from all trained health personnel on proforma (Pre designed by $\mathrm{WHO}$ ) and their certificates of training were checked.

Researcher filled the predesigned proforma at each visit at outdoor department of health facilities and observed the skills of health worker regarding assessment, classification and identification of treatment; while they were doing their routine work. Researcher encircled the "Yes" if health worker did it correctly and encircled "No" if done incorrectly. At the end of whole assessment, if health worker done correctly at $50 \%$ or more time than he was labelled as competent, otherwise labelled as incompetent.

Out of 4 health facilities 2 health facilities were visited on monthly basis (Taluka head Quarters Kotri and Government Dispensary Lower Sindh Barrage) and other 2 on quarterly basis (Government Dispensary Petaro OPD and Government Dispensary Christian colony). Assessment of health workers done during each visit.

Table I: Health worker correctly assessed a child $<5$ years (General Danger Signs, and checking of 5 main symptoms) during Quarterly visits at OPD Government Dispensary Petaro (Health worker $n=1$ )

\begin{tabular}{|c|c|c|c|c|c|c|}
\hline \multicolumn{7}{|c|}{ OPD GD Petaro } \\
\hline Month & Jan & Apr & Jul & Oct & \multirow{3}{*}{ Mean } & \multirow{3}{*}{$\begin{array}{l}\text { Standard } \\
\text { Deviation }\end{array}$} \\
\hline \multirow{2}{*}{ No. of Children } & 18 & 22 & 17 & 19 & & \\
\hline & $\mathrm{n}(\%)$ & $\mathrm{n}(\%)$ & $\mathrm{n}(\%)$ & $\mathrm{n}(\%)$ & & \\
\hline \multicolumn{7}{|c|}{ Assessment } \\
\hline Check for General Danger Signs & $8(44)$ & $13(59)$ & $11(65)$ & $14(74)$ & 11.5 & 2.646 \\
\hline Does the child have Cough or Difficult Breathing? & $11(61)$ & $15(68)$ & $12(71)$ & $14(74)$ & 13 & 1.826 \\
\hline Does the child have Diarrhea? & 11(61) & $15(68)$ & 12(71) & $14(74)$ & 13 & 1.826 \\
\hline Does the child have Sore Throat? & $8(44)$ & $13(59)$ & $11(65)$ & $14(74)$ & 11.5 & 2.646 \\
\hline Does the child have an Ear Problem? & $8(44)$ & $13(59)$ & $11(61)$ & $14(74)$ & 11.5 & 2.646 \\
\hline Does the child have Fever? (Classify malaria) & $8(44)$ & $15(68)$ & $12(71)$ & $14(74)$ & 12.25 & 3.096 \\
\hline Does the child have Fever? (classify measles) & $8(44)$ & $13(59)$ & $12(71)$ & $14(74)$ & 11.75 & 2.630 \\
\hline
\end{tabular}

After the approval by ethical committee of LUMHS (IRB Number 3484) the data was collected through a supervisory checklist for Monitoring / Supervision (Pre designed by $\mathrm{WHO}$ ) for $\mathrm{IMNCl}$ Activities. Health personnel who fulfilled the inclusion criteria were assessed / interviewed at their facility of under-five year's OPD for their practicing of $\mathrm{IMNCl}$ approach. Data was analyzed by using SPSS version 17 . All collected data (General Danger Signs, Cough or Difficult Breathing, Diarrhea, Sore Throat, ear problems, fever and measles) was entered on monthly and quarterly basis.

\section{Operational Definitions:}

Competency of Health Care Workers: We defined competency as 'having sufficient knowledge and skills to comply with predefined clinical standards.

Assessment of case management Skills of the health worker: Health worker correctly assessed a child $<5$ years (General Danger Signs, and checking of 5 main symptoms), Health worker correctly classified the child using the chart booklet, Health worker correctly treated and given appropriate pre-referral treatment at facility, Malnutrition and anemia assessed correctly, immunization status of all $<5$ years children's, Correct home advice on treatment and for follow up and checking of caretaker for correct treatment methods.

\section{RESULTS}

There was significant improvement during monthly visits as compared to Quarterly visit regarding the health workers assessment of children $<5$ years (General Danger Signs, and checking of 5 main symptoms).

Government Dispensary Lower Sindh Barrage visited monthly and OPD Government Dispensary Petaro visited quarterly, competency of staff was assessed 
Mumtaz Mahesar, Salma Shaikh, Muhammad Nadeem Chohan, Muhammad Hanif, Afshan Sultana Zia Mahesar

and compared respectively. There were better results in monthly visits as compared to quarterly visits. General Danger Signs $(11.5 \pm 2.646$ versus 8.67 \pm 3.367$)$ Cough or Difficult Breathing (13 \pm 1.826 versus $8.83 \pm 3.070)$, Diarrhea $(13 \pm 1.826$ versus 8.83 \pm 3.070$)$, Sore Throat $(11.5 \pm 2.646$ versus

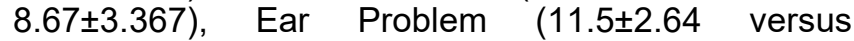
8.67 \pm 3.367$)$, malaria $(12.25 \pm 3.096$ versus $8.83 \pm 3.070)$ and measles $(11.75 \pm 2.630$ versus $8.75 \pm 3.223$ ) (Table I and III).

Taluka Head Quarters Kotri visited monthly and OPD
Government Dispensary Christian Colony visited quarterly. There were better results in monthly visits as compared to quarterly visits respectively. General Danger Signs $(9.75 \pm 3.304$ versus $7.67 \pm 3.339)$ Cough or Difficult Breathing $(11 \pm 2.944$ versus $8.08 \pm 3.260)$, Diarrhea $(11 \pm 2.944$ versus $7.92 \pm 3.476)$, Sore Throat $(10.5 \pm 3.697$ versus 8.08 \pm 3.260$)$, Ear Problem $(10 \pm 3.651$ versus $8.08 \pm 3.260)$, malaria $(10.75 \pm 2.754$ versus $8.08 \pm 3.260)$ and measles $(11 \pm 2.944$ versus 7.67 \pm 3.260 ) (Table II and IV).

Table II: Health worker correctly assessed a child $<\mathbf{5}$ years (General Danger Signs and checking of 5 main symptoms) during Quarterly visits at Government Dispensary Christian Colony. (Health Worker n=1)

\begin{tabular}{|c|c|c|c|c|c|c|}
\hline \multicolumn{7}{|c|}{ GD Christian Colony } \\
\hline Months & Jan & Apr & Jul & Oct & \multirow{3}{*}{ Mean } & \multirow{3}{*}{$\begin{array}{l}\text { Standard } \\
\text { Deviation }\end{array}$} \\
\hline \multirow{2}{*}{ No. of Children } & 16 & 24 & 18 & 21 & & \\
\hline & $\mathrm{n}(\%)$ & $\mathrm{n}(\%)$ & $\mathrm{n}(\%)$ & $\mathrm{n}(\%)$ & & \\
\hline \multicolumn{7}{|c|}{ Assessment } \\
\hline Check for General Danger Signs & $6(38)$ & $10(42)$ & $9(50)$ & $14(67)$ & 9.75 & 3.304 \\
\hline Does the child have Cough or Difficult Breathing? & $8(50)$ & $13(54)$ & $9(50)$ & $14(67)$ & 11 & 2.944 \\
\hline Does the child have Diarrhea? & $8(50)$ & $13(54)$ & $9(50)$ & 14(67) & 11 & 2.944 \\
\hline Does the child have Sore Throat? & $6(38)$ & $13(54)$ & $9(50)$ & 14(67) & 10.5 & 3.697 \\
\hline Does the child have an Ear Problem? & $6(38)$ & $12(50)$ & $8(44)$ & $14(67)$ & 10 & 3.651 \\
\hline Does the child have Fever? (Classify malaria) & $8(50)$ & $12(50)$ & $9(50)$ & $14(67)$ & 10.75 & 2.754 \\
\hline Does the child have Fever? (classify masles) & $8(50)$ & $13(54)$ & $9(50)$ & 14(67) & 11 & 2.944 \\
\hline
\end{tabular}

Table III: Health worker correctly assessed a child $<5$ years (General Danger Signs, and checking of 5 main symptoms) during Monthly Visits at Government Dispensary Lower Sindh Barrage

\begin{tabular}{|c|c|c|c|c|c|c|c|c|c|c|c|c|c|c|}
\hline \multicolumn{15}{|c|}{ Government Dispensary Lower Sindh Barrage } \\
\hline Months & Jan & Feb & Mar & Apr & May & Jun & Jul & Aug & Sep & Oct & Nov & Dec & & \\
\hline \multirow{2}{*}{ No. of Children } & 10 & 13 & 9 & 11 & 12 & 11 & 13 & 10 & 12 & 11 & 14 & 13 & Mean & SD \\
\hline & $\mathrm{n}(\%)$ & $\mathrm{n}(\%)$ & $\mathrm{n}(\%)$ & $\mathrm{n}(\%)$ & $\mathrm{n}(\%)$ & $\mathrm{n}(\%)$ & $\mathrm{n}(\%)$ & $n(\%)$ & $\mathrm{n}(\%)$ & $\mathrm{n}(\%)$ & $\mathrm{n}(\%)$ & $\mathrm{n}(\%)$ & & \\
\hline \multicolumn{15}{|c|}{ Assessment } \\
\hline $\begin{array}{l}\text { Check for General Danger } \\
\text { Signs }\end{array}$ & $3(30)$ & $6(46)$ & $6(66)$ & $9(82)$ & $10(83)$ & $10(90)$ & $12(92)$ & $3(30)$ & $11(91)$ & $10(91)$ & $13(93)$ & $11(85)$ & 8.67 & 3.367 \\
\hline $\begin{array}{l}\text { Check for General Danger } \\
\text { Signs }\end{array}$ & $3(30)$ & $6(46)$ & $6(66)$ & $9(82)$ & $10(83)$ & $10(90)$ & $12(92)$ & $3(30)$ & $11(91)$ & $10(91)$ & $13(93)$ & $11(85)$ & 8.67 & 3.367 \\
\hline $\begin{array}{l}\text { Does the child have Cough } \\
\text { or Difficult Breathing? }\end{array}$ & $4(40)$ & $6(46)$ & $6(66)$ & $9(82)$ & $10(83)$ & $10(90)$ & $12(92)$ & $4(40)$ & $11(91)$ & $10(91)$ & 13(93) & $11(85)$ & 8.83 & 3.070 \\
\hline $\begin{array}{l}\text { Does the child have } \\
\text { Diarrhea? }\end{array}$ & $4(40)$ & $6(46)$ & $6(66)$ & $9(82)$ & $10(83)$ & $10(90)$ & $12(92)$ & $4(40)$ & $11(91)$ & $10(91)$ & $13(93)$ & $11(85)$ & 8.83 & 3.070 \\
\hline $\begin{array}{l}\text { Does the child have Sore } \\
\text { Throat? }\end{array}$ & $3(30)$ & $6(46)$ & $6(66)$ & $9(82)$ & $10(83)$ & $10(90)$ & $12(92)$ & $3(30)$ & $11(91)$ & $10(91)$ & 13(93) & $11(85)$ & 8.67 & 3.367 \\
\hline $\begin{array}{l}\text { Does the child have an Ear } \\
\text { Problem? }\end{array}$ & $4(40)$ & $6(46)$ & $6(66)$ & $9(82)$ & $10(83)$ & $10(90)$ & $12(92)$ & $2(20)$ & $11(91)$ & $10(91)$ & $13(93)$ & $11(85)$ & 8.67 & 3.393 \\
\hline $\begin{array}{l}\text { Does the child have Fever? } \\
\text { (Classify malaria) }\end{array}$ & $4(4)$ & $6(46)$ & $6(66)$ & $9(82)$ & $10(83)$ & $10(90)$ & $12(92)$ & $4(40)$ & $11(91)$ & $10(91)$ & $13(93)$ & $11(85)$ & 8.83 & 3.070 \\
\hline $\begin{array}{l}\text { Does the child have Fever? } \\
\text { (classify measles) }\end{array}$ & $4(40)$ & $6(46)$ & $6(66)$ & $9(82)$ & $10(83)$ & $10(90)$ & $12(92)$ & $3(30)$ & $11(91)$ & $10(91)$ & $13(93)$ & $11(85)$ & 8.75 & 3.223 \\
\hline
\end{tabular}


Integrated Management of Childhood and Neonatal IIIness

Table IV: Health worker correctly assessed a child $<5$ years (General Danger Signs, and checking of 5 main symptoms) during Monthly Visits at Taluka Head Quarters Kotri

\begin{tabular}{|c|c|c|c|c|c|c|c|c|c|c|c|c|c|c|}
\hline \multicolumn{15}{|c|}{ THQ Kotri } \\
\hline Months & Jan & Feb & Mar & Apr & May & Jun & Jul & Aug & Sep & Oct & Nov & Dec & & \\
\hline \multirow{2}{*}{ No. of Children } & 16 & 13 & 15 & 9 & 12 & 11 & 13 & 14 & 12 & 11 & 14 & 13 & Mean & SD \\
\hline & $\mathrm{n}(\%)$ & $\mathrm{n}(\%)$ & $\mathrm{n}(\%)$ & $\mathrm{n}(\%)$ & $\mathrm{n}(\%)$ & $\mathrm{n}(\%)$ & $\mathrm{n}(\%)$ & $\mathrm{n}(\%)$ & $n(\%)$ & $\mathrm{n}(\%)$ & $\mathrm{n}(\%)$ & $\mathrm{n}(\%)$ & & \\
\hline \multicolumn{15}{|c|}{ Assessment } \\
\hline $\begin{array}{l}\text { Check for General Danger } \\
\text { Signs }\end{array}$ & $3(18)$ & $4(31)$ & $6(40)$ & $4(44)$ & $6(50)$ & $6(55)$ & $8(62)$ & $9(64)$ & $11(92)$ & 10(91) & $13(93)$ & $12(92)$ & 7.67 & 3.339 \\
\hline $\begin{array}{l}\text { Does the child have Cough } \\
\text { or Difficult Breathing? }\end{array}$ & $4(25)$ & $5(38)$ & $6(40)$ & $4(44)$ & $6(50)$ & $6(55)$ & $9(69)$ & $11(79)$ & $11(92)$ & 10(91) & $13(93)$ & $12(92)$ & 8.08 & 3.260 \\
\hline $\begin{array}{l}\text { Does the child have } \\
\text { Diarrhea? }\end{array}$ & $4(25)$ & $5(38)$ & $6(40)$ & $4(44)$ & $6(50)$ & $6(55)$ & $9(69)$ & $11(79)$ & $11(92)$ & 10(91) & 13(93) & $12(92)$ & 7.92 & 3.476 \\
\hline $\begin{array}{l}\text { Does the child have Sore } \\
\text { Throat? }\end{array}$ & $3(18)$ & $4(31)$ & $6(40)$ & $4(44)$ & $6(50)$ & $6(55)$ & $9(69)$ & $11(79)$ & $11(92)$ & 10(91) & $13(93)$ & $12(92)$ & 8.08 & 3.260 \\
\hline $\begin{array}{l}\text { Does the child have an Ear } \\
\text { Problem? }\end{array}$ & $4(25)$ & $5(38)$ & $6(40)$ & $4(44)$ & $6(50)$ & $6(55)$ & $9(69)$ & $11(79)$ & $11(92)$ & 10(91) & 13(93) & $12(92)$ & 8.08 & 3.260 \\
\hline $\begin{array}{l}\text { Does the child have Fever? } \\
\text { (Classify malaria) }\end{array}$ & $4(25)$ & $5(38)$ & $6(40)$ & $4(44)$ & $6(50)$ & $6(55)$ & $9(69)$ & $11(79)$ & $11(92)$ & 10(91) & 13(93) & $12(92)$ & 8.08 & 3.260 \\
\hline $\begin{array}{l}\text { Does the child have Fever? } \\
\text { (classify measles) }\end{array}$ & $4(25)$ & $5(38)$ & $6(40)$ & $4(44)$ & $6(50)$ & $6(55)$ & $9(69)$ & $11(79)$ & $11(92)$ & $10(91)$ & $13(93)$ & $12(92)$ & 7.67 & 3.260 \\
\hline
\end{tabular}

\section{DISCUSSION}

Frequent monitoring and evaluation of health care workers showed favorable results in many countries ${ }^{10}$. This study has been conducted to deteremine the impact of frequent follow-up visits on the $\mathrm{IMNCl}$ strategy implementation in the health facilities of district Jamshoro. In our study significant positive impact was found on improvement of health facilities of the Jamshoro district as; all foure hospitals Government Dispensary Petaro, Government Dispensary Christian Colony, Government Dispensary Lower Sindh Barrage and Taluka Head Quarters Kotri. In this study when compared the monthly monitoring with quarterly montring, there was a significant good improvement was assessd in monthly monitoring as compare to quarterly monitoring. Comparable results have been recorded in other world health organization study $^{11}$. In an Indonesian study, there was improvement in the competency of nursing staff after frequent supervision and motivation. They became perfect in recognising the emergency and priority signs after the monthly supervision ${ }^{12}$. In a study from Kenya, health workers were assessed after 2 years of initial assessment. There was not much improvement in follow up results. Initially 18 were correctly classified while after 2 years 20 children were correctly classified. Initially 60 received correct treatment while after 2 years assessment 70 children received correct assessment ${ }^{13}$. Lack of improvement in followup visit may be due to a huge gap of 2 years between first and last visit.

In this study quarterly visit done at OPD Government
Dispensary Petaro and Govenment Dispensary Christian Colony. It was checked whetherhealth worker correctly assessed a child for General Danger Signs and 5 main symptoms. On the initial visit only 8 (44.44) and 6(37.50) children were correctly assessed for general danger sign, Cough was correctly assessed in11(61.11) and 8(50.00) children; while on the last visit it was improved and 14(73.68) and 14 (66.67) children were correctly assessed for general danger sign and 14(73.68) and 14(66.67) children correctly assessed the cough. Our results are similar to a study which showed that regarding cough, 91 children were correctly assessed for the presence of fast breathing and 89 of children were correctly assessed for four general danger signs ${ }^{14}$. In a study from Rawanda, > 60 health workers correctly identified general danger signs and nutritional status of child in all 4 districts, while in Ruhango only 45 health workers correctly made the classification of diarrhea. Fever and cough was correctly classified by $>60$ health workers in all four districts ${ }^{15}$.

Regarding the assessment of Diarrhea on initial visit 11(61.11) and 8(50.00) children were assessed correctly, while on final visit 14(73.68) and 14(66.67) children were assessed correctly. In a study from South Africa results were similar to our study, 31 could not assessed dehydration, 51 could not assessed fever, 63 could not assessed malnutrion and 36 could not correctly made any serious classification ${ }^{16}$. In a study from Abbottabad $65.2 \%$ health workers correctly identified the general danger signs, while $60.8 \%$ correctly identified the plain for severe dehydration, $73.9 \%$ health workers correctly identified 
pneumonia ${ }^{17}$

Regarding Fever/Malaria on initial visit 8(44.44) and 8 (50.00) children were assessed correctly, while on final visit 14(73.68) and 10.75 children were assessed correctly. Regarding Measles on initial visit 8(44.44) 14(66.67) and 8(50.00) children were assessed correctly, while on final visit 14(73.68) and children were assessed correctly. In an international study only 28 nurses were aware of the $1 \mathrm{MNCl}$ approach that is how to assess and manage the five target diseases, which include pneumonia, diarrhea, malnutrition, measles, and malaria ${ }^{18}$. While in an indian study 68 nurses were competent in the detection and management of common conditions like acute diarrhoea, acute respiratory tract infection, fever and malaria $^{18}$.

\section{CONCLUSION}

We concluded that follow-up visits, especially monthly visits had very good impact on the IMNCl strategy implementation in the health facilities. Monitoring progress and evaluating results are key functions to improve the performance of those responsible for implementing health services.

Ethical permission: LUMHS ERC synopsis approval letter No. LUMHS/REG/ACD/1271/80, dated 24-12-2013 and Thesis approval letter No. LUMHS/ CE/PG/-774/78, dated 17-8-2018.

Conflict of Interest: There is no conflict of interest.

Funding: There was no any funding agency.

\section{REFERENCES}

1. Roser M, Ritchie H, Dadonaite B. Child \& Infant Mortality. Our World In Data. 2013. Available from: https://ourworldindata.org/child-mortality.

2. Agyepong IA, Kwamie A, Frimpong E, Defer S, Ibrahim A, Aryeeyey GC, et al. Spanning maternal, newborn and child health (MNCH) and health systems research boundaries: conducive and limiting health systems factors to improving $\mathrm{MNCH}$ outcomes in West Africa. Health Res Policy Syst. 2017; 15(Suppl 1): 54. doi:10.1186/ s12961-017-0212-x.

3. Pakistan a high child mortality country, says survey - The News [Newspaper on the Internet]. 2018 Dec 27. Available from https://www. thenews.com.pk/print/411149-pakistan-a-highchild-mortality-country-says-survey.

4. UNICEF. Situation Analysis of Children in Pakistan 2017. Unicef. Available from: https:// www.unicef.org/pakistan/media/596/file/Situation $\% 20$ Analysis $\% 20$ of $\% 20$ Children\%20in 20Pakistan.pdf.

5. Organization WH. Millennium Development Goals 4 and 5. World Health Organization. Available from: https://www.who.int/pmnch/about/about_ mdgs/en/.
6. Organization WH. 7000 newborns die every day, despite steady decrease in under-five mortality. World Health Organization. 2017. Available from: https://www.who.int/news-room/detail/19-10-20177-000-newborns-die-every-day-despite-steadydecrease-in-under-five-mortality-new-report-says.

7. Organization $\mathrm{WH}$. The world health report 2000 Health systems: improving performance. World Health Organization. 2000. Available from: https:// www. who.int/whr/2000/en/whr00_en.pdf?ua=1.

8. Organization WH. Maternal, new born, child and adolesent health: Integrated Management of Childhood Illness (IMCl). World Health Organization. 2020. Available from: https:// www.who.int/ maternal_child_adolescent/topics/ child/imci/en/.

9. Qazi AB, Hamad N, Sarwar Z, Ahmed I. Role of Monitoring and Supervision to Improve Health Service Delivery in Basic Health Units of Punjab, Pakistan. Information \& Knowledge Management. 2016; 16(1): 66-72.

10. Kabo I, Otolorin E, Williams E, Orobaton N, Abdullahi $\mathrm{H}$, Sadauki $\mathrm{H}$, et al. Monitoring maternal and newborn health outcomes in Bauchi State, Nigeria: an evaluation of a standards-based quality improvement intervention. Int $\mathrm{J}$ Qual Health Care. 2016; 28(5): 566-72.

11. Organization WH. Indonasia case study. World Health Organization. Available from: www.who. int/workforcealliance/knowledge/resources/MLHW CountryCaseStudies_annex10_Indonesia.pdf.

12. Mutungi $A$, Harvey $\bar{S}$, Kibaru J, USAID Assist. Kenya: assessment of health workforce competency and facility readiness to provide quality maternal health services. 2009. Available from: https://www.usaidassist.org/resources/kenya -assessment-health-workforce-competency-andfacility-readiness-provide-quality.

13. Baynes C, Mboya D, Likasi S, Maganga D, Pemba S, Baraka J, et al. Quality of Sick ChildCare Delivered by Community Health Workers in Tanzania. Int J Health Policy Manag. 2018; 7(12): 1097-1109.

14. Rurangirwa AA, Mogren I, Ntaganira J, Govender K, Krantz G. Quality of antenatal care services in Rwanda: assessing practices of health care providers. BMC Health Serv Res. 2018; 18(1): 865. doi:10.1186/s12913-018-3694-5.

15. Horwood C, Vermaak K, Rollins N, Haskins L, Nkosi P, Qazi S, et al. An Evaluation of the Quality of IMCI Assessments among IMCI Trained Health Workers in South Africa. PLoS ONE. 2009; 4(6): e5937. doi:10.1371/journal.pone.0005937.

16. Abrar S, Amin A, Bibi S. Coverage of $I \mathrm{MNCl}$ in district Abbottabad, Pakistan. Pak J Health Sci. 2017; 1(1): 26-28.

17. Seid SS, Sendo EG. A survey on Integrated Management of Neonatal and Childhood Illness 
implementation by nurses in four districts of West Arsi zone of Ethiopia. Pediatric Health Med Ther. 2018; 9: 1-7.

18. Debnath F, Bhatnagar $T$, Sundaramoorthy $L$, Ponnaiah M. Competency of peripheral health workers in detection \& management of common syndromic conditions under surveillance, North 24 Parganas, West Bengal, India, 2016: a crosssectional study. Glob Health Epidemiol Genom. 2017; 2: e15.

AUTHOR AFFILIATION:

Dr. Mumtaz Mahesar

Resident, Pediatric Department

Liaquat University of Medical and Health Sciences

(LUMHS), Jamshoro, Sindh-Pakistan.

\section{Dr. Salma Shaikh}

Porfessor of Pediatric Department

LUMHS, Jamshoro, Sindh-Pakistan.

Dr. Muhammad Nadeem Chohan (Corresponding Author) Assistant Professor, Pediatrics Department LUMHS, Jamshoro, Sindh-Pakistan.

Email: nadeem.chohan@lumhs.edu.pk

Dr. Muhammad Hanif

Chief Medical Officer Pediatric Department

LUMHS, Jamshoro, Sindh-Pakistan.

Dr. Afshan Sultana Zia Mahesar

Resident Obstetrics and Gynecology Department

LUMHS, Jamshoro, Sindh-Pakistan. 